\title{
Managing readers' impressions of research article abstracts through metadiscourse
}

\author{
Leah Gustilo $^{\mathbf{1}^{*}, \text { Maria Isabel Comillo }}{ }^{\mathbf{1}}$, Aileen Valle ${ }^{\mathbf{1}}$, and Rosendo III Comillo ${ }^{\mathbf{2}}$ \\ ${ }^{1,2,3}$ Department of English and Applied Linguistics, De La Salle University 2401 Taft Avenue, Malate, \\ Manila, 1004 Metro Manila, Philippines \\ ${ }^{2}$ Science Education Department, Bro. Andrew Gonzalez College of Education, De La Salle University, 2401 Taft \\ Avenue, Malate, Manila Philippines
}

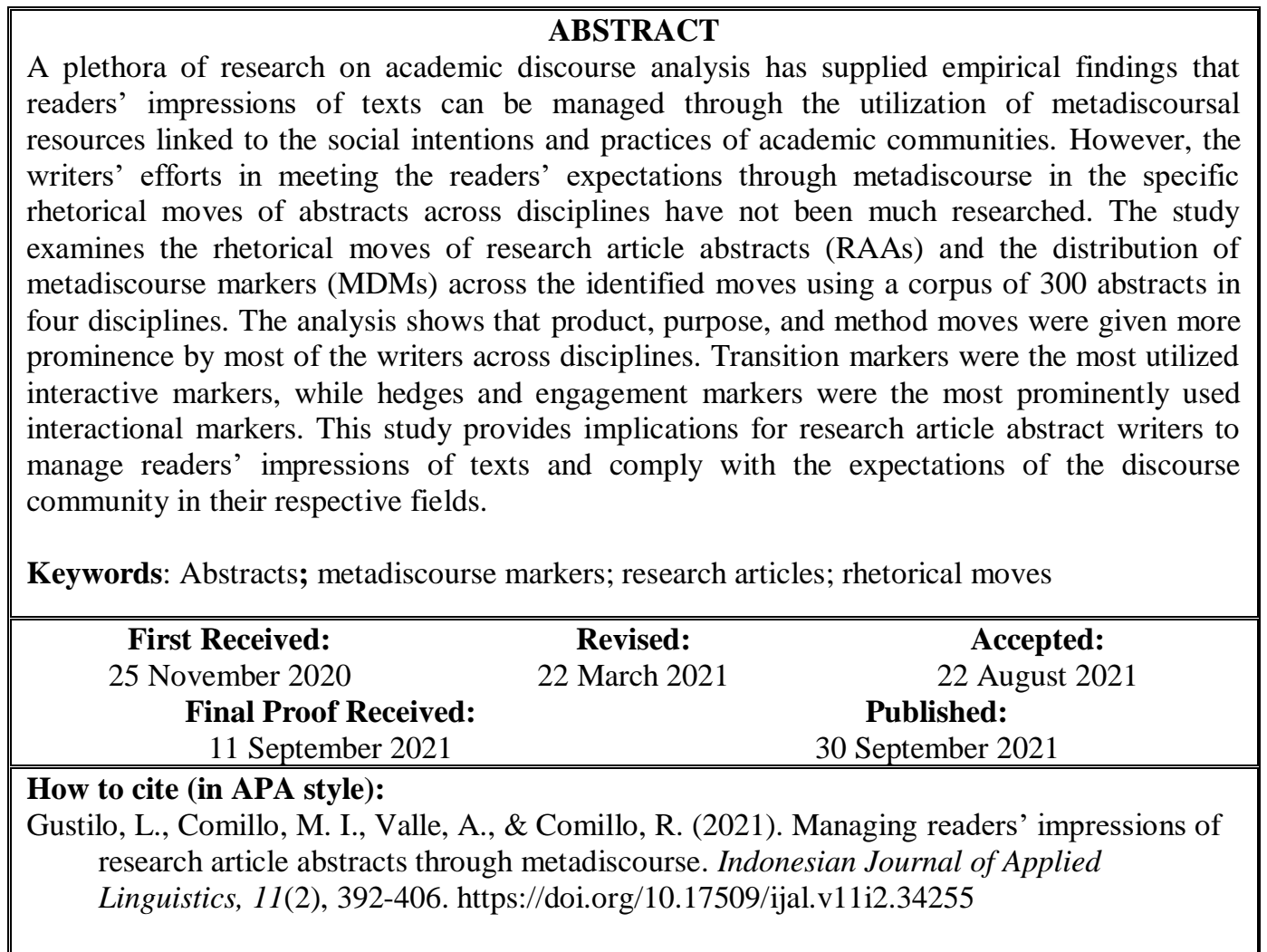

\section{INTRODUCTION}

Owing to its pivotal functions in writing research articles (henceforth, RAs), research article abstract (henceforth, RAA), a genre which is embedded in the RAs (Biber \& Conrad, 2009), has received interest from writing scholars. An abstract is the entire article's precis or 'purified' representation (Swales, 1990), the faithful summary of the whole article (Bhatia, 1993), and the abbreviated content which is prepared by its authors for publication purposes (American National Standards Institute (ANSI), 1979). The importance of research abstract is further accentuated by different authors who attached an advertising function to it, referring to abstract as the selling point of the entire article (Pho,
2008), as it becomes the 'decision-making tool' for readers to decide whether to read the entire text or purchase the articles which are sold in a pay-perarticle basis. Huckin (2006, p. 93) listed four functions of abstracts: (1) as micro texts, providing a summary of the entire article; (2) as screening tools, helping readers assess the article's worth; (3) as previews, acting as reading aids; and (4) as indexing aids, facilitating retrieval process in large databases. In addition, abstracts act as a persuasive tool (Alcaraz \& Ariza, 2020; Ren \& Li, 2011) to have the paper accepted in conferences. Authors seek to structure their abstracts effectively and persuasively knowing that their intention to disseminate their recent research and interact with other scholars in

\footnotetext{
*Corresponding Author

Email: leah.gustilo@dlsu.edu.ph
} 
their field hinges on the ability of their written abstracts to secure approval of the conference vetting committee.

Serving as the section to represent the entire article, the abstract's role in promoting the accompanying article is highly important, making it necessary for authors, especially novice authors, to learn the rhetorical patterns and linguistic features of abstract writing. The multifunctionality of RAA and the accompanying need for the effective construction of its text serve as the impetus for genre analysts to set their analytical lenses on this micro text.

Investigating the organizational structure of RAA using move-analysis, researchers have revealed the dominant move patterns, least and most frequent moves, and recurring moves that characterize abstract writing (Can et al., 2016; Darabad, 2016; Zanina, 2017) in different disciplines. Models for the rhetorical structure of abstract have been evolved by several authors (e.g. Hyland, 2000; Pho, 2008; Santos, 1996) and have been used as analytical frameworks in analyzing the structure of abstracts within disciplines (Can et al., 2016), across disciplines (Darabad, 2016), and disciplines and languages (Zanina, 2017). Similarly, a cornucopia of research can be found in databases documenting the functions of metadiscourse resources in abstracts (Jin \& Shang, 2016; Saboori \& Hashemi, 2013; Suntara \& Usaha, 2013). However, the writers' efforts in meeting the expectations of the readers through persuasive and engaging discourse using metadiscourse in the specific moves of abstracts have been scant, especially across disciplines. Hence, the present study aims at examining the rhetorical moves of RAAs and the functions of metadiscourse markers (henceforth, MDMs) in the formulation of moves across four disciplines using a larger corpus. Such investigation is expected to contribute to our understanding of genre and discipline-specific conventions in abstract writing in the scientific community, especially, in our understanding of which metadiscourse markers are associated with specific moves and how they function in each move.

Specifically, we aimed at investigating the following research questions:

1. What moves are utilized in the abstract section of Applied Linguistics, Engineering, Business, and Medicine RAs?

2. How are the authors' metadiscourse resources distributed across the different moves in the abstract section of Applied Linguistics, Engineering, Business, and Medicine RAs?

3. Is there a significant difference among the MDMs utilized by abstract writers across disciplines and moves?

\section{Previous studies on the schematic structure of RAA sections}

Within the analytical framework of genre analysis, Swales (2004) defined a move as a text segment or rhetorical unit that has an intended communicative function either in written or spoken discourse. Accordingly, one or more steps could be used to analyze a move; although in some cases, not all moves constitute a step. For Connor et al. (2007), moves characterize functional and semantic units of text that have a particular purpose. Moves and steps, therefore, deliver the purpose of the authors in writing a research article. Moves can be obligatory, optional, or conventional. Identified moves can be recurrent or non-existent in certain texts depending on the purpose of the writer.

Existing studies on the schematic structures of RAA sections have been mostly anchored on three popular models: Bhatia (1993), Hyland (2000), and Pho (2008). Generally, they consist of the vital features of an RAA section. Common features include the statement of the field to be covered or the introduction, statement of the present study to be conducted or the purpose, the method to be used, and the significant findings derived in the study. Slight alterations have been made from the earliest model to the more recent frameworks in order to better present the crucial aspects of the study.

Anchoring on these rhetorical models, numerous studies that have been conducted to investigate the schematic structure of the RAA section have shown relevant findings on how writers in different disciplines (Abdollahpour \& Gholami, 2018; Al-Shujairi et al., 2016; Can et al., 2016; Darabad, 2016; Suntara \& Usaha, 2013) with varied L1 backgrounds (Al-Khasawneh, 2017; Gheinani \& Tabatabaei, 2018) organized their ideas in presenting the abstract of RAs. On the whole, the majority of the previous studies was framed by Hyland's (2000) five-move model whose popularity could be attributed to the simplicity of the model compared to other existing models. In terms of the rhetorical structures, purpose, method, and product appeared to be the most frequently used moves across disciplines. The native writers (L1 English speakers) frequently observed the introduction and conclusion moves than the non-native (ESL or EFL) writers did. Contrastive studies have documented that writers incorporate certain patterns in presenting the vital features of RAAs which vary across disciplines and among writers from different language backgrounds.

\section{Previous studies on metadiscourse in RAAs}

Worded in many different ways but referred to similarly by different scholars, metadiscourse refers to the linguistic impression management resources (Hyland \& Tse, 2004) that help writers organize the information flow and enable readers to understand the textual content and the writers' attitude towards 
the audience. These are resources, spoken or written, that do not add propositional content in discourse but help the audience to organize, interpret, evaluate and react to the propositional content presented to them (Crismore et al., 1993; Whitt, 2018). Hyland (2005) refers to metadiscourse as self-reflective expressions that help writers express their viewpoints, negotiate interactional meanings, and promote engagement with their readers.

Several metadiscourse models have been proposed by different linguists and scholars. The earliest model proposed by Vande (1985) outlined two types of metadiscourse: textual markers (e.g. code glosses, narrators, connectives, and illocution markers) and interpersonal markers (e.g. attitude markers, validity markers, and commentaries). Crismore et al. (1993) introduced a revised model of Vande's (1985) framework by retaining the two main types of metadiscourse but subdividing textual metadiscourse into textual and interpretative markers. The most well-applied model was created by Hyland (2005) which divides metadiscourse into two classes: interactive metadiscourse and interactional metadiscourse. Interactive metadiscourse resources are aimed at making the text organized and persuasive; interactional metadiscourse signals are aimed at getting readers to recognize the writer's viewpoints on propositional content, orientation, and intention in relation to the readers. This is the model that was utilized in the present study.

Over the past decades, increasing attention has been given to the analysis of MDMs in RAAs (Akoto, 2020). Investigations on the types and functions of metadiscourse in specific disciplines utilizing Hyland's (2000) model has been widely undertaken by researchers (Gillaerts \& Van de Velde, 2010; Mocanu, 2015). The most common findings from these previous studies attest to the importance of boosters in convincing the readers to read the entire article, hedges to soften their claim, and attitude markers to show the attitude of the writers towards their proposition.

In addition, several findings on the usage of metadiscourse across different disciplines were also documented. Teeming with results are studies comparing the field of Applied Linguistics with other disciplines (Jin \& Shang, 2016; Saboori \& Hashemi, 2013; Suntara \& Usaha, 2013) whose common findings attest to the dominant use of interactive MDMs over interactional markers and the prominence of transition markers in almost all disciplines. Cross-disciplinary differences exist in the distribution and specific context of the use of these markers that mirror discipline-specific conventions and social practices embedded in different writing contexts (Khedri et al., 2013). However, to our knowledge, only one study analyzed the utilization of MDMs in smaller discourse units such as moves. Mardiana (2015) analyzed the rhetorical structures and use of metadiscourse across rhetorical moves in the English abstracts of undergraduate students' articles. Mardiana revealed that transitions, which were more pronounced in Move 4 (Product), and frame markers, which were mostly located in Move 2 (purpose), occurred most frequently. Boosters and attitude markers were associated with Move 4 (Product). The scantiness of research documenting writers' strategic efforts in managing readers' impressions through metadiscourse in the specific moves of abstracts justifies the aims of the present study.

\section{METHOD}

The present research is corpus-based and descriptive in nature; it focuses on the analysis of MDMs used in RAAs across disciplines. Specifically, the present study describes the distributional patterns of moves and the utilization of MDMs in the realization of these moves in the abstract sections of four disciplines under investigation.

\section{Corpus}

The present study's corpus consists of 300 abstracts of RAs from four disciplines, namely: Applied Linguistics, Engineering, Business, and Medicine. Seventy-five abstracts published over the period of three years (2015-2017) from each discipline were selected through systematic random sampling. A total of 122,102 words comprised the dataset from four sub-corpora: Applied Linguistics $(26,796)$, Engineering (26,021), Business (21,789), and Medicine $(47,496)$. The average length of the abstracts is 150 words.

The choice of the journals was motivated by the following considerations: (1) impact factor of the journal, (2) number of publications per year, and (3) availability of articles in each discipline. Specifically, the corpus was extracted from the following journals:

1. Applied Linguistics: System (1.547 IF)

2. Engineering: International Journal of Advanced Research in Electrical, Electronics, and Instrumentation Engineering (6.392 IF)

3. Business: Journal of Business Research (3.354 IF)

4. Medicine: BMC Medicine (8.285 IF)

\section{Data analysis}

The data analysis for this study comprised three stages. First, in examining the rhetorical moves, Hyland's (2000) five-move framework was used. Upon identifying the communicative function for each move, color coding was assigned in each sentence or T-unit identified as a move: (1) yellow for the introduction, (2) red for purpose, (3) blue for method, (4) green for product, and (5) purple for the 
conclusion. In this stage, an inter-coder agreement was computed between the analysis of two intercoders.

Second, Hyland's (2005) list of MDMs was used to locate the MDMs used in each move; then the identified moves from the abstracts were saved in separate files and categorized according to move per discipline. Each file per move was then examined using AntConc 3.5.2 Concordance Software to easily identify the markers present in each move. Manual analysis was conducted to verify the occurrence of MDMs in the abstracts.

Finally, the tabulated frequency count for the MDMs across moves and disciplines was used as data for the test of significant difference using the log-likelihood test.

\section{Reliability}

To ensure the reliability of the categorization of moves, the second and the third authors of this study independently identified the moves in all 300 abstracts. The results of the inter-coder agreement for the independent coding of moves varied per discipline (see Table 1). In Applied Linguistics, $74.9 \%$ agreement was computed; $65.6 \%$ agreement in Engineering; $93.2 \%$ in Medicine, and $64.5 \%$ in Business. The average inter-coder agreement for all disciplines is $74.57 \%$. In the final analysis, a hundred percent agreement was achieved in all moves identified by the two authors after they reviewed together with the functions of MDMs identified in the text.

Table 1

Percentage of Agreement across Moves in Four Disciplines

\begin{tabular}{lcccc} 
& Applied Linguistics & Engineering & Medicine & Business \\
\hline Introduction & $56.0 \%$ & $70.0 \%$ & $99.3 \%$ & $68.7 \%$ \\
Purpose & $75.3 \%$ & $92.0 \%$ & $66.7 \%$ & $76.0 \%$ \\
Method & $80.7 \%$ & $73.3 \%$ & $100.0 \%$ & $60.0 \%$ \\
Product & $82.7 \%$ & $62.7 \%$ & $100.0 \%$ & $72.6 \%$ \\
Conclusion & $80.0 \%$ & $30.0 \%$ & $100.0 \%$ & $45.3 \%$ \\
AGREEMENT per discipline & $\mathbf{7 4 . 9 \%}$ & $\mathbf{6 5 . 6 \%}$ & $\mathbf{9 3 . 2 \%}$ & $\mathbf{6 4 . 5 \%}$ \\
\hline Average percentage of agreement & & & $\mathbf{7 4 . 5 7 \%}$ & \\
\hline
\end{tabular}

\section{FINDINGS AND DISCUSSION}

\section{Moves in research article abstracts}

Our move-based analysis of RAAs has demonstrated that the rhetorical organization of abstracts in our selected corpus showed crossdisciplinary rhetorical differences based on the frequency distribution of moves across disciplines (see Table 2) and the analysis on the essentiality of moves (see Table 3). Table 2 presents the frequency of moves that occurred in the abstracts and the percentage of each move out of the total number of moves. Most of the Applied Linguistics RAAs had four or five moves. The most frequently used moves were Purpose, method, and Product at $100 \%$, which means that these moves were present in all abstracts in our dataset for Applied Linguistics. They were also the most frequent moves found by Can et al. (2016) in their analysis of Applied Linguistics abstracts from the English for Specific Purposes journal. Giving background information in the Introduction move appears to be less important for Applied Linguistics abstract writers as this move appeared only in $43 \%$ of the abstracts.

Table 2

Frequency Distribution of Moves across Disciplines

\begin{tabular}{|c|c|c|c|c|c|c|c|c|c|c|c|}
\hline & \multicolumn{2}{|c|}{$\begin{array}{c}\text { Move 1 } \\
\text { Introduction }\end{array}$} & \multicolumn{2}{|c|}{$\begin{array}{l}\text { Move } 2 \\
\text { Purpose }\end{array}$} & \multicolumn{2}{|c|}{$\begin{array}{l}\text { Move } 3 \\
\text { Method }\end{array}$} & \multicolumn{2}{|c|}{$\begin{array}{l}\text { Move } 4 \\
\text { Product }\end{array}$} & \multicolumn{2}{|c|}{$\begin{array}{c}\text { Move 5 } \\
\text { Conclusion }\end{array}$} & \\
\hline & $\mathrm{f}$ & $\%$ & $\mathrm{f}$ & $\%$ & $f$ & $\%$ & $\mathrm{f}$ & $\%$ & $f$ & $\%$ & \\
\hline Applied Linguistics & 40 & 53.3 & 75 & 100.0 & 75 & 100.0 & 72 & 96.0 & 64 & 85.3 & 326 \\
\hline Engineering & 54 & 72.0 & 73 & 97.3 & 60 & 80.0 & 56 & 74.6 & 25 & 33.3 & 268 \\
\hline Business & 49 & 65.3 & 50 & 66.6 & 31 & 41.3 & 60 & 80.0 & 73 & 97.3 & 263 \\
\hline Medicine & 75 & 100.0 & 60 & 80.0 & 75 & 100.0 & 75 & 100.0 & 75 & 100.0 & 360 \\
\hline Total & 218 & & 258 & & 241 & & 263 & & 237 & & \\
\hline
\end{tabular}

Table 3

Essentiality of Moves Across Disciplines

\begin{tabular}{|c|c|c|c|c|c|c|c|c|c|c|}
\hline & \multicolumn{2}{|c|}{$\begin{array}{c}\text { Move 1 } \\
\text { Introduction }\end{array}$} & \multicolumn{2}{|c|}{$\begin{array}{l}\text { Move } 2 \\
\text { Purpose }\end{array}$} & \multicolumn{2}{|c|}{$\begin{array}{l}\text { Move } 3 \\
\text { Method }\end{array}$} & \multicolumn{2}{|c|}{$\begin{array}{l}\text { Move } 4 \\
\text { Product }\end{array}$} & \multicolumn{2}{|c|}{$\begin{array}{c}\text { Move } 5 \\
\text { Conclusion }\end{array}$} \\
\hline & & $\%$ & & $\%$ & $\mathrm{E}$ & $\%$ & E & $\%$ & $\mathrm{E}$ & $\%$ \\
\hline Linguistics & Opt & 53.33 & Oblig & 100.00 & Oblig & 100.00 & Conv & 96.00 & Conv & 85.33 \\
\hline Engineering & Conv & 72.00 & Conv & 97.33 & Conv & 80.00 & Conv & 74.67 & Opt & 33.33 \\
\hline Business & Conv & 65.33 & Conv & 66.67 & Opt & 41.33 & Conv & 80.00 & Conv & 97.33 \\
\hline Medicine & Oblig & 100.00 & Conv & 80.00 & Oblig & 100.00 & Oblig & 100.00 & Oblig & 100.00 \\
\hline
\end{tabular}

Legend: Opt: optional, Conv: conventional, Oblig: obligatory 
In Engineering, the most frequent move was Purpose which appeared in $73(97.3 \%)$ out of 75 Engineering abstracts. The second most frequent move was method which was found in 60 (80\%) out of 75 abstracts. The third most utilized move was Product which occurred in $56(74.6 \%)$ abstracts. Compared to Applied Linguistics abstracts, conclusion $(33.3 \%)$ was the least utilized move in Engineering abstracts.

In the Business research abstracts, the most frequent move was Conclusion at $97.3 \%$. The second most utilized move which appeared in 60 $(80 \%)$ abstracts was product. Method, which appeared in less than half of the abstracts (41.3\%), was the least frequent move. The prominence of conclusion move in Business abstracts suggests that in this field, abstract writers prioritized the generalizations and recommendations that the field could gain out of the empirical findings of the study. Lastly, abstracts in the field of Medicine preferred a five-move scheme, confirming previous findings that all five moves are frequently used, making these moves as constant schematic features in Medical abstracts (Abdollahpour \& Gholami, 2018). Introduction, method, product, and conclusion moves appeared in all abstracts. Purpose move, although it did not appear in all abstracts, still has a high occurrence $(80 \%)$ in the dataset for Medical abstracts.

With regard to Engineering abstracts, no obligatory move was found. Conclusion is an optional move, and the rest are conventional moves. This striking result suggests that writers in the Engineering field are more flexible and are not boxed by any writing models, confirming the comparative study of San and Tan (2012) that the five-move model is not the norm for writing abstracts in the field of Computer and Communication Systems Engineering. In their study, Introduction and Purpose moves were obligatory for both groups of writers, while for the rest of the moves, the writers have different preferences. In their study, the Conclusion move has also the lowest frequency of utilization. In the present study, Engineering is the second field with the least number of move occurrences.

Regarding the Business abstracts, no obligatory move was found-the same results for Engineering abstracts. Introduction, purpose, product, and conclusion are conventional moves; while the method is an optional move. This finding suggests that writers in Business abstracts do not allot too much space for the discussion of methods, putting less prominence on the process of investigation.

Lastly, in the Medicine dataset, introduction, method, product, and conclusion are obligatory moves. Purpose move occurred in $80 \%$ of the medical abstracts, making it a conventional move. Of the four disciplines analyzed, Medical abstracts have the greatest number of obligatory moves, indicating that introduction, method, product, and conclusion are the most expected communicative functions in medical abstracts. One striking disciplinary feature of medical abstracts is that the obligatoriness of the Introduction move can only be found in this field. The prominence placed on the Introduction move suggests that abstract writers in the Medicine field need to "market" their research by emphasizing its centrality and relevance for the advancement of the discipline (Mur-Dueñas, 2014). Overall, most of the abstract writers across disciplines put more importance on the discussion of results (product), purpose, and method in their abstracts as these are the three moves with the highest frequencies. This present finding corroborates the findings of previous studies (cf., Al-Shujairi et al., 2016; Suntara \& Usaha, 2013), giving us more substantiated claims that the prominence of these three moves suggests crossdisciplinary consistency when it comes to giving importance to reporting the results, announcing the purpose, and outlining the processes of the study. Most especially, offering the results of the investigation (product) appears to be the most crucial move as it emerged as the most frequent of all moves, although it was not always obligatory in every discipline investigated.

Contextualizing the study by offering initial background information (Introduction) appeared to be less important to the abstract writers in all disciplines under study except for the Medical field wherein setting the background of the study is a salient move. The differences in frequencies may be connected to the obligatoriness and optionality of the moves or to what the writers consider as the most important information that can attract the attention of the readers in the abstracts. As abstract is the most compressed section of RAs, the most frequent moves abstract writers utilize in this section should give us a signal that they are the most salient information that can introduce the accompanying research article. Abstract writers believe that announcing their purposes, outlining the processes of the study, and reporting the findings could hook their readers into reading or buying their research articles.

\section{Distribution of MDMs across moves}

The next analysis enquires into the utilization of metadiscourse resources across the five moves of RAAs. Our quantitative analysis of the four datasets indicates that abstract writers aimed to manage the readers' impressions by utilizing MDMs that effectively express their viewpoints, negotiate interactional meanings, and promote engagement with their readers. However, as we have already pointed out in the review of literature on metadiscourse studies, the different social and discipline-specific factors constituting the contexts 
of abstract writing necessitated varied ways of utilizing interpersonal resources that resulted in significant differences in the distribution of metadiscourse markers. The 4,885 MDMs found in the dataset are composed of 3,112 (64\%) interactive MDMs and 1,773 (36\%) interactional MDMs. Tables 4 and 5 provide an overall view of these differences in the four datasets analyzed. Table 4 provides a frequency-based (per 1,000 words) view of these differences with regard to the interactive MDMs, while Table 5 presents the frequency-based (per 1,000 words) variations as regards the interactional MDMs.

Table 4

Frequencies of Interactive Metadiscourse in Four Disciplines (per 1,000 words)

\begin{tabular}{|c|c|c|c|c|c|c|}
\hline 2 & $\begin{array}{c}\text { Code } \\
\text { Glosses }\end{array}$ & $\begin{array}{c}\text { Endophoric } \\
\text { Markers }\end{array}$ & Evidentials & $\begin{array}{c}\text { Frame } \\
\text { Markers }\end{array}$ & $\begin{array}{c}\text { Transition } \\
\text { Markers }\end{array}$ & $\begin{array}{c}\text { Total Normalized } \\
\text { Frequency }\end{array}$ \\
\hline \multicolumn{7}{|l|}{ Applied Linguistics } \\
\hline Introduction & 0.6 & 0 & 0 & 0 & 3.2 & 3.88 \\
\hline Purpose & 0.4 & 0 & 0 & 0.5 & 3.1 & 3.99 \\
\hline Method & 0.6 & 0 & 0 & 0.6 & 5.6 & 6.75 \\
\hline Product & 0.9 & 0.1 & 0 & 0.3 & 7.9 & 9.14 \\
\hline Conclusion & 0.2 & 0 & 0 & 0.1 & 3.1 & 3.4 \\
\hline Subtotal & 2.7 & 0.1 & 0 & 1.5 & 22.9 & 27.2 \\
\hline \multicolumn{7}{|l|}{ Engineering } \\
\hline Introduction & 0.8 & 0 & 0 & 0.2 & 6.1 & 7.19 \\
\hline Purpose & 0.3 & 0 & 0 & 0.9 & 3.3 & 4.65 \\
\hline Method & 0.3 & 0.1 & 0 & 0.7 & 5.3 & 6.53 \\
\hline Product & 0.5 & 0 & 0 & 0.7 & 4.3 & 5.5 \\
\hline Conclusion & 0 & 0 & 0 & 0.3 & 1 & 1.27 \\
\hline Subtotal & 1.9 & 0.1 & 0 & 2.8 & 20 & 25.1 \\
\hline \multicolumn{7}{|l|}{ Business } \\
\hline Introduction & 0.6 & 0 & 0 & 0.1 & 4.8 & 5.55 \\
\hline Purpose & 0.1 & 0 & 0 & 0.3 & 4.5 & 4.91 \\
\hline Method & 0.2 & 0 & 0 & 0.4 & 2.3 & 2.94 \\
\hline Product & 0.7 & 0 & 0 & 0.5 & 7.5 & 8.72 \\
\hline Conclusion & 0 & 0 & 0 & 0 & 2.4 & 2.39 \\
\hline Subtotal & 1.6 & 0 & 0 & 1.3 & 21.5 & 24.5 \\
\hline \multicolumn{7}{|l|}{ Medicine } \\
\hline Introduction & 0.4 & 0 & 0 & 0.3 & 2.9 & 3.6 \\
\hline Purpose & 0.1 & 0 & 0 & 0.2 & 1.2 & 1.49 \\
\hline Method & 1.1 & 0 & 4 & 0.2 & 6.6 & 7.96 \\
\hline Product & 0.9 & 0 & 0 & 0 & 7.2 & 8.19 \\
\hline Conclusion & 0.4 & 0 & 0 & 0.1 & 3.5 & 3.94 \\
\hline Subtotal & 2.9 & 0 & 0.1 & 0.7 & 21.4 & 25.1 \\
\hline
\end{tabular}

As can be seen in Table 4, Applied Linguistics has the greatest number of interactive MDMs per 1,000 words (27.2); it is followed by Medicine (25.1) and Engineering (25.1). Business has the least number of interactive MDMs (24.5). Specifically, transition markers were observed as the most frequently used interactive MDMs across the five moves in all the disciplines. Authors across disciplines did not see the importance of evidential and endophoric markers in guiding the readers through the texts as these markers rarely occurred in our four datasets.

In the field of Applied Linguistics, a total of 613 transition markers or 23 per 1,000 words were noted across the five moves. Code glosses and frame markers were also used but with fewer frequencies. Evidentials occurred only in medical abstracts, and endophoric markers appeared only in Applied linguistics and in Engineering abstracts with low frequencies. The highest frequency of interactive MDMs occurred in product moves (9.14). Method move displayed the second-highest number of interactive MDMs (6.75). Conclusion move (3.4) has the least number of interactive MDMs. The high frequency of interactive MDMs, especially transition markers, in the product move is indicative of the importance that Applied linguists attached to these markers in maintaining the coherence of the text particularly in presenting the findings found in the study.

Similarly, transition markers are prevalent in Engineering abstracts (20 per 1,000 words). Engineers also used frame markers and code glosses with low frequencies. Like the Applied linguistics abstracts, endophoric markers and evidential were not relied on by Engineering abstract writers. Interactive MDMs were more frequently utilized in Introduction move (7.19), then in method move (6.53), Product move (5.5), and Purpose move (4.65). Conclusion move (1.27) displayed the least number of markers. This finding suggests that Engineers see the essentiality of guiding their readers more effectively in the organization of Introduction wherein they describe the context and 
nature of the study. Given the complicated terminologies in Engineering texts, Engineers, see the need to achieve coherent writing in the Introduction move.

Table 5

Frequencies of Interactional Metadiscourse in Four Disciplines (per 1,000 words)

\begin{tabular}{|c|c|c|c|c|c|c|}
\hline & $\begin{array}{l}\text { Attitude } \\
\text { Markers }\end{array}$ & Boosters & $\begin{array}{c}\text { Self- } \\
\text { Mentions }\end{array}$ & $\begin{array}{c}\text { Engagement } \\
\text { Markers }\end{array}$ & Hedges & $\begin{array}{c}\text { Total Normalized } \\
\text { Frequency }\end{array}$ \\
\hline \multicolumn{7}{|l|}{ Applied Linguistics } \\
\hline Introduction & 0.5 & 0.5 & 0.1 & 1.3 & 1.2 & 3.51 \\
\hline Purpose & 0.0 & 0.0 & 0.4 & 0.9 & 0.3 & 1.60 \\
\hline Method & 0.2 & 0.2 & 0.2 & 1.0 & 0.3 & 1.94 \\
\hline Product & 1.0 & 2.3 & 0.2 & 2.4 & 2.4 & 8.28 \\
\hline Conclusion & 0.3 & 0.3 & 0.5 & 1.5 & 1.6 & 4.11 \\
\hline Total & 2.0 & 3.3 & 1.4 & 7.1 & 5.8 & 19.4 \\
\hline \multicolumn{7}{|l|}{ Engineering } \\
\hline Introduction & 0.7 & 0.3 & 0.2 & 2.1 & 1.1 & 4.34 \\
\hline Purpose & 0.2 & 0.1 & 0.4 & 1.1 & 0.3 & 2.11 \\
\hline Method & 0.1 & 0.3 & 0.3 & 1.0 & 0.2 & 1.92 \\
\hline Product & 0.3 & 1.2 & 0.2 & 1.1 & 0.7 & 3.38 \\
\hline Conclusion & 0.1 & 0.0 & 0.2 & 0.3 & 0.0 & 0.65 \\
\hline Total & 1.4 & 1.9 & 1.3 & 5.6 & 2.3 & 12.4 \\
\hline \multicolumn{7}{|l|}{ Business } \\
\hline Introduction & 0.6 & 0.3 & 0.2 & 1.4 & 2.0 & 4.50 \\
\hline Purpose & 0.1 & 0.1 & 0.4 & 0.6 & 0.4 & 1.61 \\
\hline Method & 0.0 & 0.4 & 0.3 & 0.5 & 0 & 1.24 \\
\hline Product & 1.2 & 1.7 & 0.6 & 1.9 & 3.3 & 8.67 \\
\hline Conclusion & 0.1 & 0.0 & 0.2 & 0.6 & 0.6 & 1.56 \\
\hline Total & 2.0 & 2.5 & 1.7 & 5.0 & 6.3 & 17.6 \\
\hline \multicolumn{7}{|l|}{ Medicine } \\
\hline Introduction & 0.4 & 0.4 & 0.1 & 0.6 & 0.9 & 2.48 \\
\hline Purpose & 0.1 & 0.0 & 0.1 & 0.5 & 0.0 & 0.74 \\
\hline Method & 0.0 & 0.1 & 0.4 & 0.7 & 0.3 & 1.58 \\
\hline Product & 0.3 & 0.8 & 0.2 & 0.6 & 1.6 & 3.5 \\
\hline Conclusion & 0.3 & 0.3 & 0.2 & 0.7 & 1.7 & 3.2 \\
\hline Total & 1.2 & 1.5 & 1.1 & 3.1 & 4.5 & 11.5 \\
\hline
\end{tabular}

In Medicine, Product move displayed the highest frequency of interactive markers (8.19), while Purpose move has the least number of markers (1.49). Similar to the other disciplines, the most frequently used marker was transition markers (21.4 per 1,000 words). Accordingly, the prominence of transition markers in the Product move could be attributed to the complicatedness of the nature of medical findings often discussed in medical articles. Maintaining coherence of the information presented in this move is necessary to aid the readers in understanding the complex medical findings presented in the study.

Lastly, regarding the Business abstracts, only three types of markers were observed across the moves: transition markers which displayed the highest frequency (21.5), code glosses (1.6), and frame markers (1.3). In particular, the Product move (8.72) displayed the greatest number of markers, then the Introduction move (5.55) and the Purpose move (4.91). The Conclusion move (2.39) displayed the least number of markers.

Our closer look at the transitional makers reveals the most frequent sub-categories that constitute this category. Consistently used in all disciplines under the study, Addition (and, also) and Comparison (e.g. but, although, however) were the most frequently occurring transitional markers, especially in the product (Results/Discussion) move. And, also, but, although, and however are the top five most frequent transitional markers in our dataset.

Overall, it is interesting to highlight the finding that all abstract writers in the four disciplines under study equally put transition markers in the pedestal by using them more frequently but differently across moves depending on where they think it is more important according to the communicative needs of the discipline where they belong. Applied linguists, medical researchers, and business researchers saw a greater need to achieve coherence in writing the Product section, while engineers see the cruciality of coherence in setting the background of the study (Introduction move). Our present results corroborated some findings of Zarei and Mansoori (2007) who noted that text coherence is more emphasized than the interpersonal functions of language by Applied Linguistics and Computer Engineering research articles. Further, Wang and Zhang (2016) reiterated the crucial role of transition markers in maintaining the coherence of text such as in the case of an abstract since its nature is to summarize the important findings of the entire articles; the use of transition markers is deemed 
important in connecting each idea presented in the abstract. The current finding on the prominence of transition markers in Product move is in line with the study of Mardiana (2015) who also reported high occurrences of transition markers in Product move.

Similarly, the use of interactional MDMs was equally important; it allows writers to express their stance and engage readers in discourse. Table 5 presents the frequency per 1,000 words of interactional MDMs used across moves in our four datasets. Applied Linguistics (19.4), Business (17.6), and Engineering (12.4) abstracts utilized higher frequencies of interactional MDMs. Medical abstracts utilized the least number of interactional MDMs (11.5). Hedges were the most frequently utilized interactional markers (4.5), followed by engagement markers (3.1). Attitude markers, boosters, and self-mentions rarely occurred in the abstracts across disciplines.

Various interactional MDMs were observed across the different moves. In the field of Applied Linguistics, the Product move (8.28) contained the greatest number of interactional MDMs with hedges (2.4) and engagement markers (2.4) having the highest frequency of occurrence. In contrast, the Purpose move (1.6) employed the least number of markers. In Engineering, the highest occurrence of markers was observed in the Introduction move (4.34) with engagement markers (2.1) being the most prominently used marker. Conclusion move (.65) employed the least number of markers. In Business, Product move constituted 8.67 interactional MDMs in which 3.3 of these were hedges. On the other hand, the method move (1.24) manifested the least number of interactional MDM. Finally, in Medicine, the highest occurrence of markers was noted in the product move (3.5) with hedges (1.6) as the most frequently used marker. On the other hand, the purpose move (.74) employed the least number of markers.

Our closer analysis of the hedging devices reveals that suggest, about, indicate, may, could, should, and likely were the most frequently occurring interactional MDMs. They were utilized more frequently in the Product move, especially in Applied Linguistics, Business, and Medicine. Hyland (1995, pp. 34-35) believes that there are three reasons for the use of hedging devices: (1) they allow writers to state propositions or scientific claims with caution and greater precision; (2) hedges enable writers to lower their responsibility and limit damage to their reputations due to categorical commitments; and (3) hedges help develop the author-audience relationship, which achieves cooperation in obtaining approval of the writer's claims. Hedges signal the author's unwillingness to express propositional content categorically (Hyland \& Tse, 2004). Based on the present findings, it appears that abstract writers from
Applied Linguistics, Business, and Medicine rely heavily on hedges to decrease their responsibility in expressing their proposition towards the discussion of the results of the study. For instance, in medical abstracts, hedges may be needed in the Product move in order to make the writers' claims about their medical findings less categorical. Hyland (2006) argues that "because of the uncertain status of much medical knowledge, writers often need to present their claims cautiously, accurately, and modestly to meet the exacting expectations of a skeptical community. Hence, hedges are commonplace in medical writing to express possibility and deference rather than certainty and overconfidence" (p. 694). The findings of the present study confirm the findings of Liu and Buckingham (2018) who also found hedges to be the most frequent interactional MDM in the results and discussion section of research articles in Applied Linguistics. They claimed that hedges in this section of the article are used by writers to "attenuate or nuance their commitment to the evaluations and recommendations they draw from their study". (p. 105). The prominence of hedges in Business abstracts in the present study, especially in the Product move, is in line with the findings of Alyousef (2015) who showed that international postgraduate business students also highly utilize hedges in their multimodal finance texts especially when commenting on their results using graphs and figures. The use of hedges by abstract writers could have been framed by an awareness of the compulsion to temper personal conviction and to achieve effective persuasion that is in line with the community or disciplinary practice (Hyland, 1999).

The present findings corroborated previous findings (cf. Liu \& Buckingham 2018; Taki \& Jafarpour, 2012) which claimed that hedges are one of the most frequently used interactional MDMs in academic writing. The prominence of hedges could be attributed to its role in "imbuing the author's interpretation of the results with greater persuasive quality" by trying to withhold commitment to their claims (Crismore \& Abdollehzadeh, 2010; Hyland, 1998). In the present findings, only engineering abstract writers utilized this resource less frequently. This fewer utilization of hedges by engineers corroborates Kahkesh and Alipour's (2017) finding who found fewer occurrences of hedges in engineering RAs compared to literature RAs. The use of fewer hedges in engineering abstracts is justifiable considering the nature of communicative expectations in the engineering discipline which allows writers to show more certainty in reporting technical or empirical data.

Further, the use of engagement markers is prominent in the fields of Engineering and Applied Linguistics, which clearly suggests that writers in these fields pay more attention to engaging their readers in the discourse. The most prominent 
engagement markers in the data of these two disciplines are Reader Pronouns we and our. Abstract writers used these engagement markers in order to signal to the readers that they are included in the dialogue, having similar intentions and understanding as to the author (Hyland, 2005). Incorporating Reader Pronouns such as we, you, your, and our allows writers to give the readers a sense of membership in the discourse.

Overall, although the need for coherence outweighs the value of interactional relationships in abstract writing, the present results attest that academic discourse is not an impersonal dialogue because it utilizes dialogic and interactional resources to engage the readers (Taki \& Jafarpour, 2012).

\section{Test of significant difference across disciplines} and across moves

The final layer of analysis was undertaken to enquire if the differences in the occurrences of moves and MDMs across disciplines are statistically significant. Our results reveal an overall significant difference between interactive and interactional MDMs across disciplines with the log-likelihood value of 9.15 for interactive markers and 91.51 for interactional markers (see Appendixes A and B). Likewise, individual analysis for interactive and interactional MDMs on each move showed significant differences across disciplines.

The test of significant differences across moves shows overall significant differences among interactive and interactional MDMs with the loglikelihood value of 9.77 and 239.35 for interactive and interactional MDMs, respectively (see Appendixes C and D). Specifically, an individual analysis also reveals statistically a significant difference among the markers in each discipline across the five moves. The present results confirm previous findings of Nelson and Castello (2012 as cited in Livytska, 2019) who claimed that metadiscourse shows significant differences across disciplines.

\section{CONCLUSION}

This present study focused on the rhetorical moves and functions and distribution of MDMs in the formulation of moves written by abstract writers in Applied Linguistics, Medicine, Business, and Engineering fields with an intention to contribute to our understanding of genre and discipline-specific conventions in abstract writing in the scientific community.

The findings of the present study corroborate the reliability of the rhetorical organization of abstracts proposed by Hyland (2000). The five moves are present in most of the abstracts of four disciplines, whose varied frequencies can be attributed to the obligatoriness, conventionality, and optionality of the discourse units which are intended to meet the communicative expectations of the discourse communities in different disciplines under investigation. These findings are worthy of celebration because they help establish the conventions and writing cultures in different communities of practice within the academic community. However, what is more, celebratory is the contribution of the present analysis to the understanding of the utilization of MDMs across different moves of the research article abstracts in four disciplines.

There are pronounced similarities in the distribution of interactive and interpersonal MDMs across moves in four disciplines. As previously discussed, both categories of MDMs occurred more frequently in the Product (Results/Discussion) section of Applied linguistics, Business, and Medicine abstracts, signaling a message to the discourse community of these disciplines that it is in the results/discussion section that writers exert more effort in managing the information flow in order to affect their intended interpretation.

MDMs indeed provide linguistic impression management resources for writers to utilize in order to control readers' impressions of the texts, guide the readers' interpretation, establish a certain level of intimacy between writers and readers, and project the writers' attitudes and commitments to their propositions (Hyland, 2004; Kuhi \& Benham, 2011).

In the light of the foregoing findings, we identified possible instructional implications. Foremost, a genre-based approach to teaching academic writing exposing students to the rhetorical organizations and move features of abstracts in different disciplines can make novice writers become aware of the appropriate and acceptable structures that comply with the expectations of the discourse community in their field.

Furthermore, another instructional application is in relation to the functions of MDMs in the realization of the communicative purposes of moves. An instructional material based on research findings such as this study would prove beneficial in helping writers identify the specific MDMs that achieve the specific purposes in the process of writing the discourse units in a particular discipline. As discussed in the foregoing section, such MDMs aid in the logical flow of ideas in the text and in maintaining interpersonal relationships with the readers. Overall, exploring these specific aspects of writing can equip writers with valuable insights regarding the standards and norms of academic writing in different disciplines.

\section{REFERENCES}

Akoto, O, Y. (2020). Metadiscourse within a discipline: A study of introduction and 
literature review chapters of sociology masters' theses. Indonesian Journal of Applied Linguistics 10(2), 471-480. https://doi.org/10.17509/ijal.v10i2.28588

Alyousef, H. M. (2015). An investigation of metadiscourse features in international postgraduate business students' texts: The use of interactive and interactional markers in tertiary multimodal finance texts. Sage Open, 5(4), 1-10. https://doi.org/10.1177/2158244015610796

Abdollahpour, Z., \& Gholami, J. (2018). Building blocks of medical abstracts: Frequency, functions and structures of lexical bundles. The Asian ESP Journal, 14(1), 83-111.

Al-Khasawneh, F. M. (2017). A genre analysis of research article abstracts written by native and non-native speakers of English. Journal of Applied Linguistics and Language Research, 4(1), 1-13.

Al-Shujairi, Y. B., Ya’u, M., \& Buba, A. (2016). Role of moves, tenses, and metadiscourse in the abstract of an acceptable research article. Mediterranean Journal of Social Sciences, 7(2), 379-386.

Alcaraz, D. I., \& Ariza, M. A. (2020). Research paper abstract in Monthly Notices of the Royal Astronomical Society (1943-2018): A diachronic approach focusing on linguistic and authorial implications. English text Construction, 13(1), 62-83.

Bhatia, V. (1993). Analysing genre: Language use in professional settings. Longman.

Biber, D., \& Conrad, S. (2009). Register, genre, and style. Cambridge University Press.

Can, S., Karabacak, E., \& Qin, J. (2016). Structure of moves in research article abstracts in applied linguistics. Publications, 4(3), 23-39. https://doi.org/10.3390/publications4030023

Crismore, A. \& Abdollehzadeh, E. (2010). A review of recent metadiscourse studies: The Iranian context. Nordic Journal of English Studies, 9(2), pp.195-219. http://doi.org/10.35360/njes.223

Crismore, A., Markkanen, R., \& Steffensen, M. (1993). Metadiscourse in persuasive writing: A study of texts written by American and Finnish university students. Written Communication, 10(1), 39-71. https://doi.org/10.1177/0741088393010001002

Connor, U., Upton, T. A., \&Kanoksilpatham, B. (2007). Introduction to move analysis. In D. Biber, U. Connor, \& T. A. Upton (Eds.), Discourse on the move: Using corpus analysis to describe discourse structure (pp. 23-41). John Benjamins Publishing Company.

Darabad, A. M. (2016). Move analysis of research article abstracts: A cross-disciplinary studies. International Journal of Linguistics, 8(2), 125140. https://doi.org/10.5296/ijl.v8i2.9379
Gheinani, M. T., \& Tabatabaei, O. (2018). A structural move analysis of the abstract section of ISI articles of Iranian and native scholars in the field of agricultural engineering. International Journal of Research Studies in Language Learning, 7(3), 109-122. https://doi.org/10.5861/IJRSLL.2017.1864

Gillaerts, P., \& Van de Velde, F. (2010). Interactional metadiscourse in research article abstract. Journal of English for Academic Purposes, 9(2), 128-139. https://doi.org/10.1016/j.jeap.2010.02.004

Huckin, T. (2006). Abstracting from abstracts. In M. Hewings (Ed.), Academic writing in context: Implications and applications (pp. 93-103). Birmingham University Press.

Hyland, K. (1995). The author in the text: Hedging scientific writing. Hongkong Papers in Linguistics and Language Teaching, 18, 33-42.

Hyland, K. (1998). Hedging in Scientific Articles. Hong Kong Journal of Applied Linguistics, 3(2), 133-136.

Hyland, K. (1999). Talking to students: Metadiscourse in introductory coursebooks. English for Specific Purposes, 18, 3-26.

Hyland, K. (2000). Disciplinary discourses: Social interactions in academic writing. Pearson Education.

Hyland, K. (2005). Metadiscourse: Exploring interaction in writing. Continuum.

Hyland, K. (2006) Medical discourse: Hedges. In K. Brown (ed.-in-chief) Encyclopedia of Language and Linguistics (2 ${ }^{\text {nd }}$ ed.), 694-697. Elsevier.

Hyland, K., \& Tse, P. (2004). Metadiscourse in academic writing: A reappraisal. Applied Linguistics, 25(2), 156-177. http://doi.org/10.1093/applin/25.2.156

Kahkesh, M., \& Alipour, M.A. (2017). A comparative analysis of metadiscourse markers in the result and discussion sections of literature and engineering research papers. Iranian Journal of Applied Language Studies, 9, 71-82. https://doi.org/10.22111/ijals.2018.4192

Khedri, M., Ebrahimi, S., \& Heng, C. (2013). Interactional metadiscourse markers in academic research article result and discussion sections. 3L: Language, Linguistics, Literature ${ }^{\circledR}, 19(1), 65-74$.

Kuhi, D., \& Benham., B. (2011). Generic variations and metadiscourse use in writing of applied linguists: A comparative study and preliminary framework. Written Communication, 28(1), 97-141. https://doi.org/10.1177\%2F074108831038725 9

Jin, X., \& Shang, Y. (2016). Analyzing metadiscourse in the English abstracts of BA 
theses. Journal of Language Teaching and Research, 7(1), 210-215.

Liu, Y., \& Buckingham, L. (2018). The schematic structure of discussion sections in applied linguistics and the distribution of metadiscourse markers. Journal of English for Academic Purposes, 34, 97-109. https://doi.org/10.1016/j.jeap.2018.04.002

Livytska, I. (2019). The use of hedging in research articles on applied linguistics. Journal of Language and Cultural Education, 7(1), 35-53.

Mardiana, W. (2015). Metadiscourse and rhetorical moves in English abstract section of undergradruate students' (thesis) articiles at STKIP PGRI Jombang [Unpublished Master's thesis]. Diponegoro University, Indonesia.

Mocanu, M. (2015). An empirical analysis of metadiscourse in the abstracts of Romanian accounting research articles. Accounting and Management Information Systems, 14(2), 362377.

Mur-Dueñas, P. (2014). 'The main contribuition of this study is...': An analysis of statements of contribution in English published research articles and L2 manuscripts. Journal of Writing Research, 5(3), 271-283. https://doi.org/10.17239/jowr-2014.05.03.2

Pho, P. (2008). Research article abstracts in applied linguistics and educational technology: A study of linguistic realizations of rhetorical structure and authorial stance. Discourse Studies, 10(2), 231-250. https://doi.org/10.1177/1461445607087010

Ren, H., \& Li, Y. (2011). A comparison study on the rhetorical moves of abstracts in published research articles and master's Foreignlanguage theses. English Language Teaching, 4(1), 162-166. https://doi.org/10.5539/elt.v4n1p162

Saboori, F., \& Hashemi, M. (2013). A crossdisciplinary move analysis of research article abstracts. International Journal of Language Learning \& Applied Linguistics World, 4(4), 483-496.

San, L. Y., \& Tan, H. (2012). A comparative study of the rhetorical moves in abstracts of published research articles and students' term papers in the field of computer and communication systems engineering. International Journal of Applied Linguistics and English Literature, 1(7), 40-50.

Suntara, W., \& Usaha, S. (2013). Research article abstracts in two related disciplines: Rhetorical variation between linguistics and applied linguistics. English Language Teaching, 6, 8499. https://doi.org/10.5539/elt.v6n2p84

Swales, J. (1990). Genre analysis: English in academic and research settings. Cambridge University Press.

Swales, J. (2004). Research genres: Explorations and applications. Cambridge University Press.

Taki, S., \& Jafarpour, F. (2012). Engagement and stance in academic writing: A study of English and Persian research articles. Mediterranean Journal of Social Sciences, 3(1), 157-168.

Vande, K. (1985). Some explanatory discourse on metadiscourse. College Composition and Communication, 36(1), 82-93.

Wang, L., \& Zhang, Y. (2016). An analysis of metadiscourse in the abstracts of English academic papers. Global Journal of HumanSocial Science, 16(9). https://socialscienceresearch.org/index.php/GJ HSS/article/download/1922/1860/

Whitt, R. (2018). "And all this is spoken of the natural byrth..." Metadiscourse in The Birth of Mankind and its German source text, Rosengarten. English Text Construction, 11(2), 226-256. https://doi.org/10.1075/etc.00010.whi

Zanina, E. (2017). Move structure of research article abstracts on Management: Contrastive study (the case of English and Russian). Journal of Language and Education, 3(2), 63-72.

Zarei, G. R., \& Mansoori, S. (2007). Metadiscourse in academic prose: A contrastive analysis of English and Persian research articles. The Asian ESP Journal, 3(2), 24-40. http://asianesp-journal.com/wpcontent/uploads/2016/01/AESP-Volume-3Issue-2-November-2007.pdf 


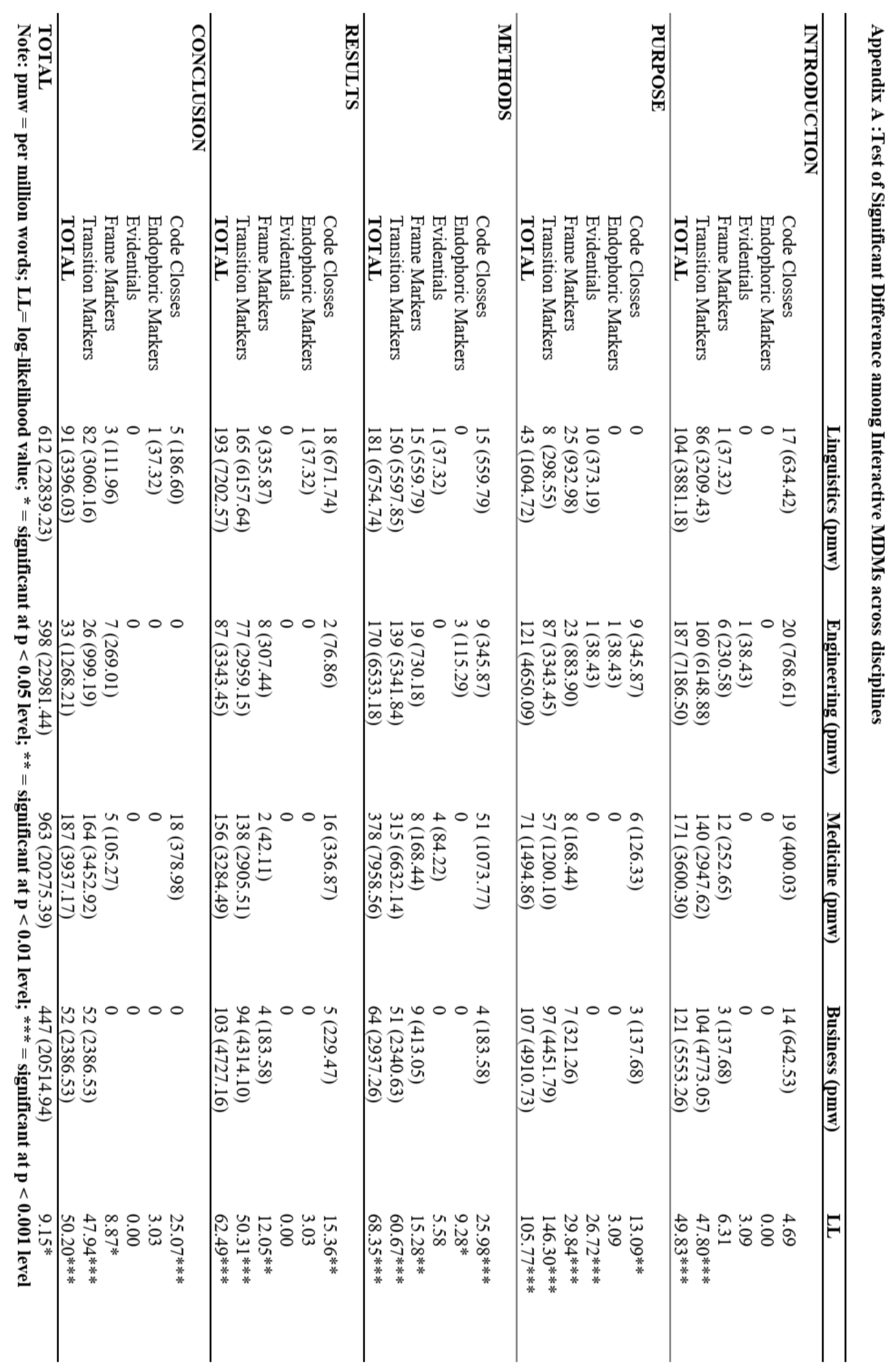




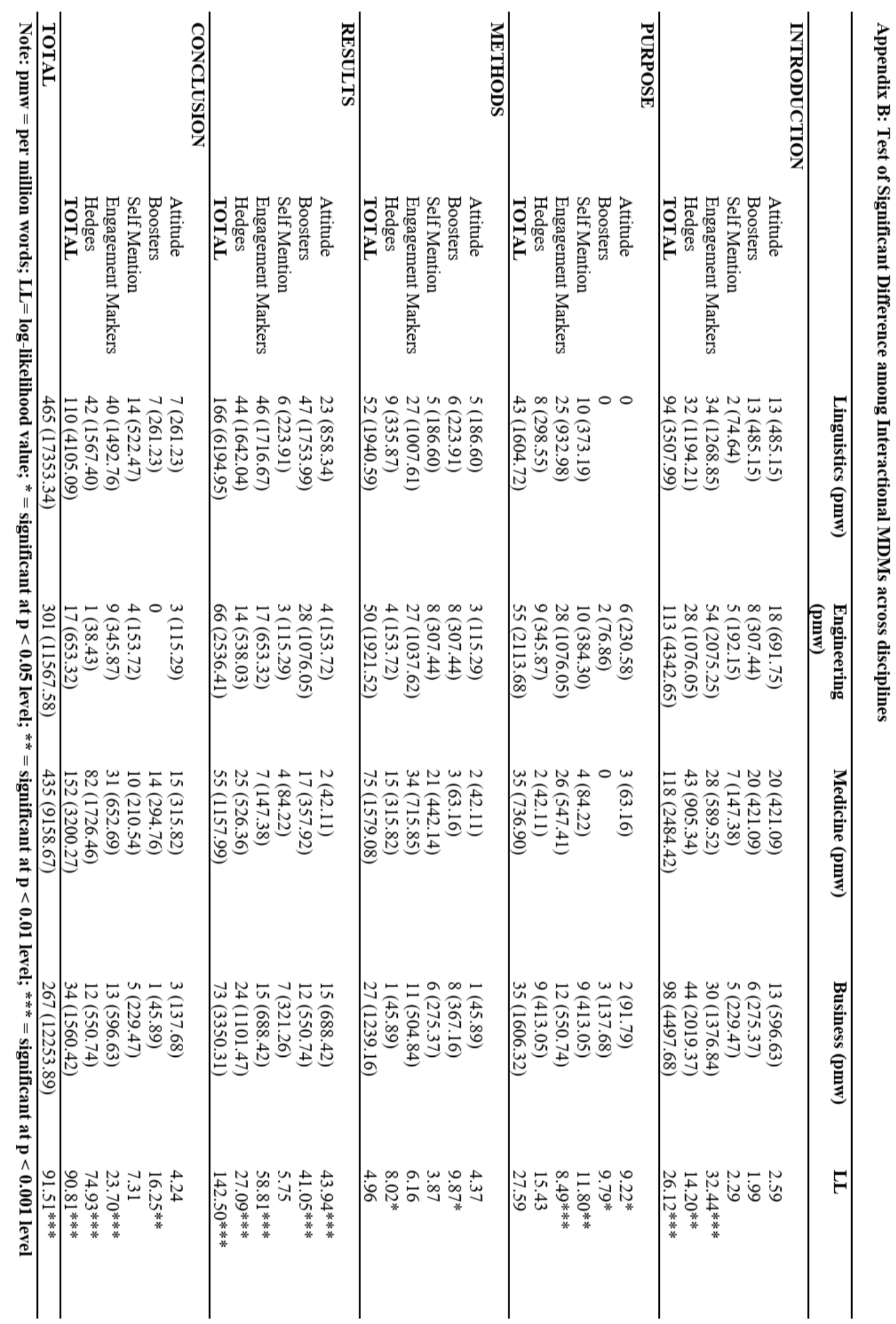




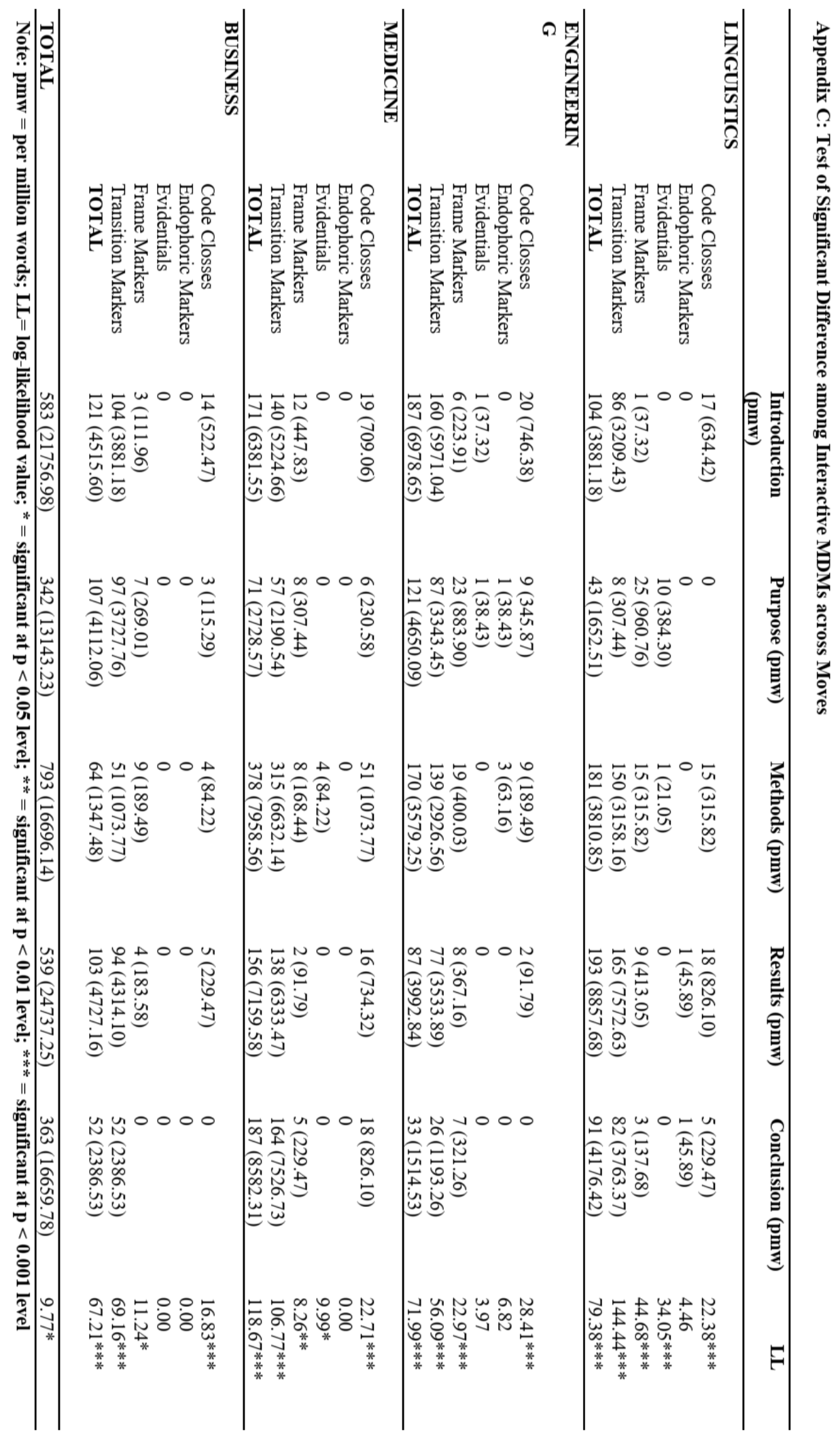




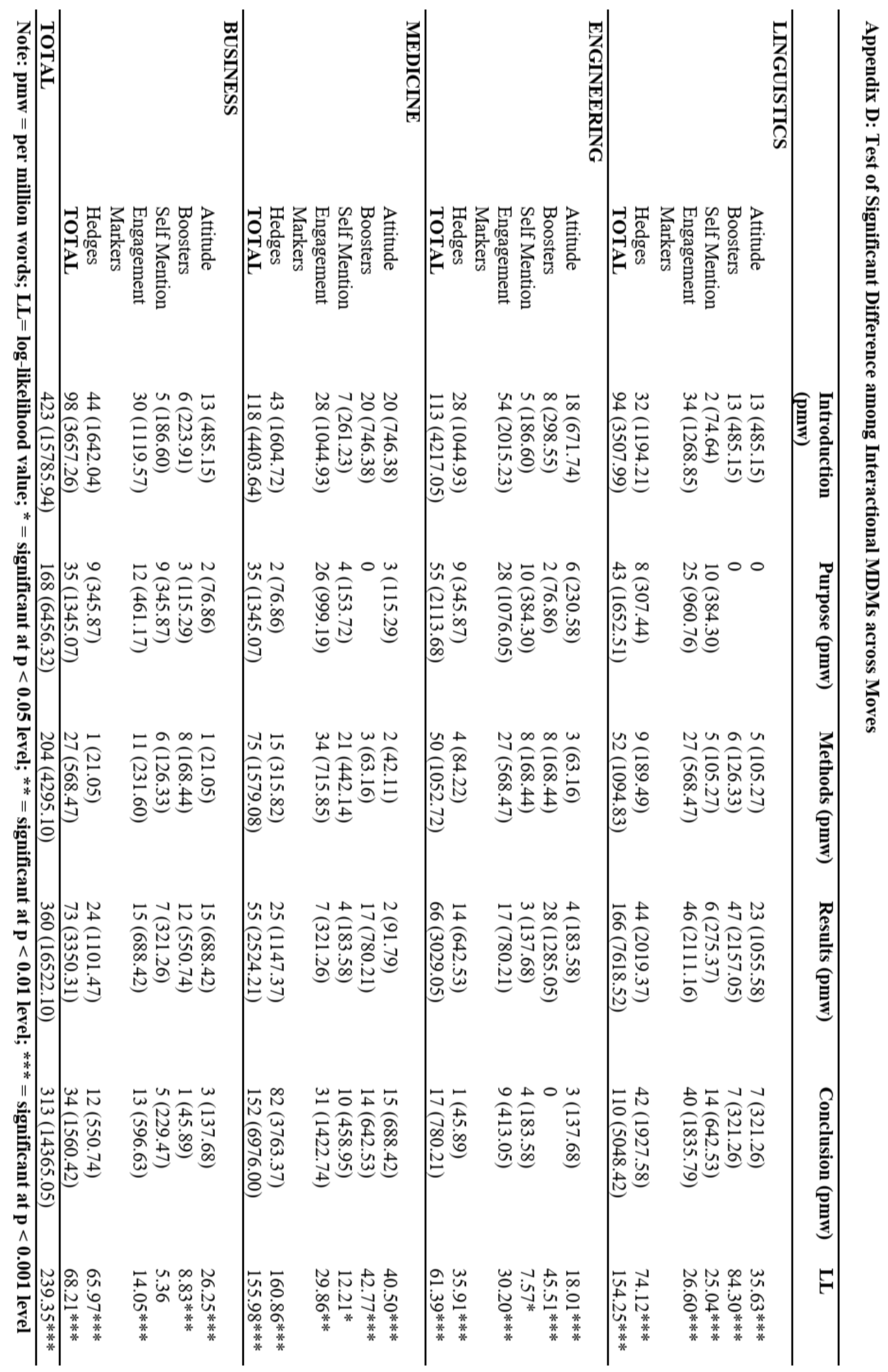

